\title{
Grid Management through Vehicle-To-Grid Technology
}

\author{
Bakul Vani, Devyani Chaturvedi, Preeti Yadav
}

\begin{abstract}
This research paper is based on a project which is a prototype on a smaller level of integrating vehicle-to-grid technology at the residential and commercial levels which can be expanded in future with the help of bi-directional AC-DC power converters and Control systems. Vehicle-to-Grid is a technology that allows energy to be supplied back to the power grid from the battery of an electric car for fulfilling the excess demand on the grid. It is depicted in the prototype with the help of TP charging module and embedded system i.e. Arduino to manage the ever-increasing energy demand from the grid. With the increasing environmental problems, modern automobile technology is innovating in the field of Electric Vehicles (EV) with lesser pollution and better efficiency. This has attracted a lot of attention, but the major hindrance faced is the availability of energy required to maintain the grid is resonance. We can overcome this by vehicle-to-grid technology in smart parking systems. When the $E V$ is parked, energy may be drawn out or supplied to the $E V$ through the grid depending upon the requirements of the grid and the vehicle's battery. The implementation of this technology enables the stored energy in the electric vehicle to be transferred to the power grid and vice-versa.[13]

Keywords: Vehicle-to-Grid (V2G); Grid Management; Electric Vehicle (EV); Charging Station; Demand Side; Embedded system; Switching circuits.
\end{abstract}

\section{INTRODUCTION}

G Trid management is the monitoring and control of the demand that is placed on the generating station with the help of alternate present day technologies which involve a combination of distributed generation (DG) such as various renewable energy sources as well as vehicle to grid concept. Vehicle to Grid is an important tool in the grid management process, and therefore is the concept of our project. There persists a variance in the amount of power demanded and supplied in any given power system. Unexpected failure in a power plant, indispensable loads, miscalculation in forecasting the load, or climatic conditions bring about peak demands in the system. Fulfilling such heavy demands is expensive for a certain power plant or generator in terms of efficiency and reliability. The increasing integration of distributed energy generation of various hybrid consumers and suppliers has led to a requirement of managing the spike in load with the existing resources in the system. [1]

Manuscript received on May 30, 2021

Revised Manuscript received on June 06, 2021.

Manuscript published on July 30, 2021.

* Correspondence Author

Ms. Bakul Vani*, B.Tech Student, Department of Electrical Engineering, Medi-Caps University, Indore (Madhya Pradesh), India.

Ms. Devyani Chaturvedi, B.Tech Student, Department of Electrical Engineering, Medi-Caps University, Indore (Madhya Pradesh), India.

Ms. Preeti Yadav, Assistant Professor, Department of Electrical Engineering Medi-Caps University, Indore (Madhya Pradesh), India.

(C) The Authors. Published by Blue Eyes Intelligence Engineering and Sciences Publication (BEIESP). This is an open access article under the CC BY-NC-ND license (http://creativecommons.org/licenses/by-nc-nd/4.0/)
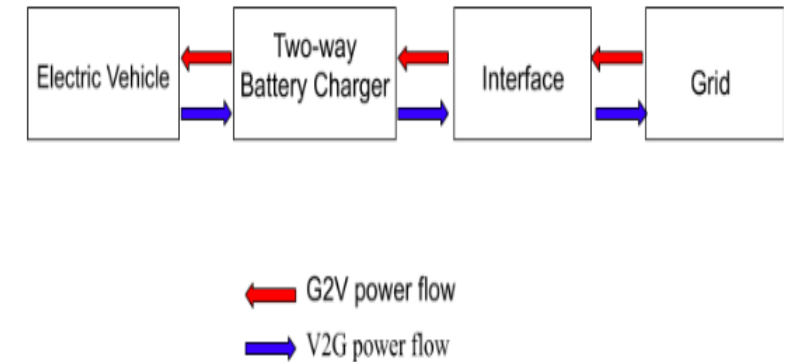

This figure represents a power flow block diagram of V2G technology.

\section{VEHICLE-TO-GRID TECHNOLOGY}

V2G i.e. 'Vehicle-to-Grid' is a technology that allows energy to be sent back to the power grid from the battery of an electric car for the benefit of the grid. With Vehicle-toGrid technology, a car can be charged and discharged based on different signals. The notion is that Electric Vehicles and their batteries represent a mobile power resource from which power can be withdrawn when the vehicle is not being used for transportation. The wavering power demand generates heavy loads that cannot be covered by the power plant's generator and must be balanced out by the public power grid.[1] This will play a crucial role in the ancillary services market, which addresses power grids' continual need for stabilization. V2G has an upper hand because it can stabilize the grid closer to the demand endpoints.

\section{PROBLEM IDENTIFICATION}

Non-renewable sources are powerful energy providers, However, we have exhausted their deposits within only the last few centuries. The biggest reason for climate change is the emission of greenhouse gases. Factually, it is clear that we have to change how we generate and use energy. This consists of electric vehicles along with the shift to renewable energy which causes the problem of storing energy.[15] Renewable sources like Wind and Solar need energy to be either used where it's produced or stored somewhere for later usage. Since, the advancement of renewables unavoidably makes our energy system more volatile, thus requiring new ways to balance and store energy to be used. This is where electric vehicles come into play which are usually parked for the majority of the day. This parked time can better be utilised as a temporary stationary energy storage which can be pushed back to the power grid when there is rise in energy demand.[15] Electric vehicle batteries are by far the most cost-efficient form of energy storage since they require no additional investments in hardware.

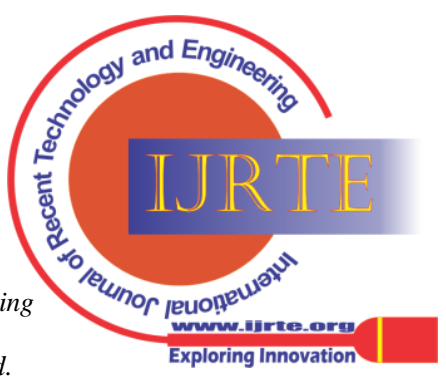




\section{TECHNOLOGY AND HARDWARE USED}

The technology and hardware used in this project are as follows-

\subsection{Arduino Uno}

In this project, the embedded system used is Arduino Uno which is used as the interface for controlling. The Arduino Uno is a microcontroller which is developed on the concept of ATmega328 and runs at 5V. It has 14 digital input/output pins, 6 analog inputs (A0 - A5), a $16 \mathrm{MHz}$ ceramic resonator, a power jack, a USB connecting port, an ICSP header, and a reset button. It is powered by the USB connection. It has the capability to read analog or digital input signals and convert it into an output such as activating a motor, turning LED on/off, and other switching purposes.

\subsection{Arduino IDE}

The Arduino IDE (Integrated Development Environment) is a software that connects to the Arduino UNO hardware to upload programs and for communication. The Arduino Software (IDE) consists of a text editor, a text console, a message area, a toolbar, and a set of menus.

\subsection{Relay}

Relay is an electronic switch. It has a set of input terminals for a single or multiple control signals, and a set of operating contact terminals. It is interfaced with microcontrollers, for instance, Arduino, PIC etc. Status of the relay is indicated through a LED.

\subsection{Sensors}

A Sensor converts a physical parameter into a signal which can be measured electrically. The obtained data can be interpreted by either a human or a machine.

a. Voltage Sensor. A voltage sensor calculates and monitors the amount of voltage in a circuit. It detects both $\mathrm{AC}$ and DC voltage levels.

- Input Voltage: 0 to $25 \mathrm{~V}$

- Voltage Detection Range: 0.02445 to $25 \mathrm{~V}$

b. Current Sensor. A current sensor senses electric current in the line and produces a signal equivalent to the current. It works with both Alternating and Direct Current. Current sensors measure current passively, without interrupting the circuit. The current sensor being used is the ACS712 Module.

- Operating voltage: 0 to $5 \mathrm{~V}$

- Available as 5A, 20A, and 30A module

\subsection{Lithium-Ion Battery}

A lithium-ion battery is a type of rechargeable battery. These batteries are used in portable electronics and electric vehicles. Type: 18650

- Nominal Voltage- $3.7 \mathrm{~V}$

- Capacity- 2400 mAh

\subsection{TP Charging Module}

TP4056 charging module is a small 3.7V single lithiumion cell charging module. It can charge various kinds of 3.7V li-ion batteries.

- Battery type: Lithium-Ion

- Battery Voltage: 3.7-4.2 V

- Current: $1 \mathrm{~A}$
- Input Voltage: 4-8 V

- Output Voltage: $4.2 \mathrm{~V}$

4.7 Loads

a. LED. A light-emitting diode (LED) is a semiconductor light source that emits light when current flows through it.

- $\quad$ Operating Voltage (V): 1.8 to 3.3

- $\quad$ Rated Current (mA): 20 to 40

b. DC Motor. The DC Motor is the most commonly used electric motor which is used for the conversion of electrical energy into mechanical energy. It produces continuous movement and its speed of rotation can be controlled easily.

- Operating Voltage(V): 12

- $\quad$ Rated Speed (RPM): 200

- $\quad$ Rated Torque(kg-cm): 1.5

- $\quad$ Load Current (A): 0.3

- $\quad$ No Load Current (A): 0.6

4.8 Power Adapter. An adapter is a device that is plugged into a wall outlet. It initially converts the power to the desired voltage level and then the adapter converts the AC to DC using a setup called a rectifier.

- Input rated range: $90 \mathrm{Vac}-270 \mathrm{Vac}$

- Input frequency: $50 / 60 \mathrm{~Hz}$

- Output voltage: $12.0 \mathrm{~V}$

- Output current: 1 A

\section{HARDWARE DESIGN}

The connections for the experimental setup that was used to understand the mechanism of the V2G technology are detailed below. The adapter acts as the grid power supply ( $220 \mathrm{~V}$ AC to $12 \mathrm{~V} \mathrm{DC}$ ). The Arduino uno is powered from a USB cable coming from a computer that is terminated in a barrel jack. It is being used to load code on the Arduino board. $5 \mathrm{~V} \mathrm{DC}$ (Arduino) powers relay 1, relay 2, relay 3 $(+\mathrm{V})$. The digital pins 5,6 and 7 of the Arduino UNO board are connected to input pins of relay 1 , relay 2, relay 3 respectively. Grid power supply is connected to the load through relay 1. Load is connected to the EV's through relay 2. Relay 3 is connected between grid power supply and TP charging module. $5 \mathrm{~V}$ DC (Arduino) powers current sensor 1 and 2 (VCC; connected in parallel). The analog pins A0, A1 and A2 of the Arduino UNO board are connected to the Output pins of Current sensor 1, 2 and voltage sensor. Current sensor 1 is connected in series between the grid power supply and load. Current sensor 2 is connected in series between load and EV battery. Voltage sensor is connected in parallel to the EV's battery.

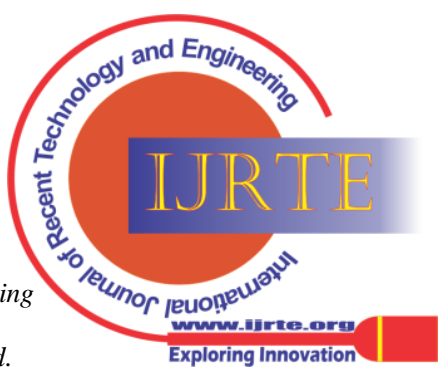


Positive power supply (12 V DC transformed to 5V DC) powers the TP charging module at input positive through Relay 3. Negative of the grid power supply is connected to the input negative of the Charging module. Output positive of TP charging module and Common of the relay 2 connected to the positive of EV's battery. Output negative of the TP charging module is connected to the negative of EV's battery. Ground pins of current sensor 1, current sensor 2, relay 1 , relay 2 and relay 3 are connected together and grounded.

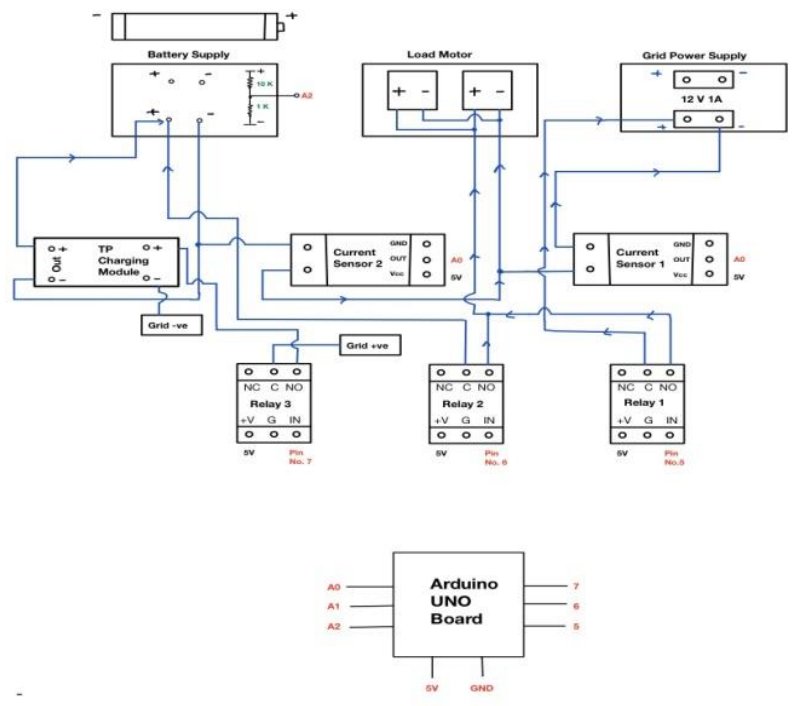

The figure shown above is the circuit diagram of the prototype on which the V2G concept was implemented.

\section{METHODOLOGY}

The working of the hardware designed above explaining the concept of V2G during which readings were taken is as follows-

- Initially, when there is sufficient power on the grid for the demanded load, the load (motors) runs on the power from the grid (220 V AC to $12 \mathrm{~V} \mathrm{DC}$ ) through relay 1. (Refer to Table I i.e. Case A)

- As soon as the load demand or the current consumption on the load side increases more than 0.25 A (Refer to Table II i.e. Case-B) as the set value for limited power generation (measured through current sensor 1 connected to load) and power from the grid is insufficient to fulfill the excess load demand, the motor load shifts on the power supply from the EV's battery. ( Refer to Table III i.e. CaseC)

- This process continues and the State-of-charge of the battery gradually starts decreasing. When the stateof-charge of EV's battery falls below $3.5 \mathrm{~V}$ as the set value for minimum SoC ( measured by the voltage sensor that is connected to EV's battery), the power supply from the EV's battery to the load stops and the battery is scheduled for charging from the grid i.e. power supply. ( Refer to Observation 2 in Table III i.e. in Case C)

- This cycle continues in a loop until the power supply is switched off.

\section{FLOWCHART}

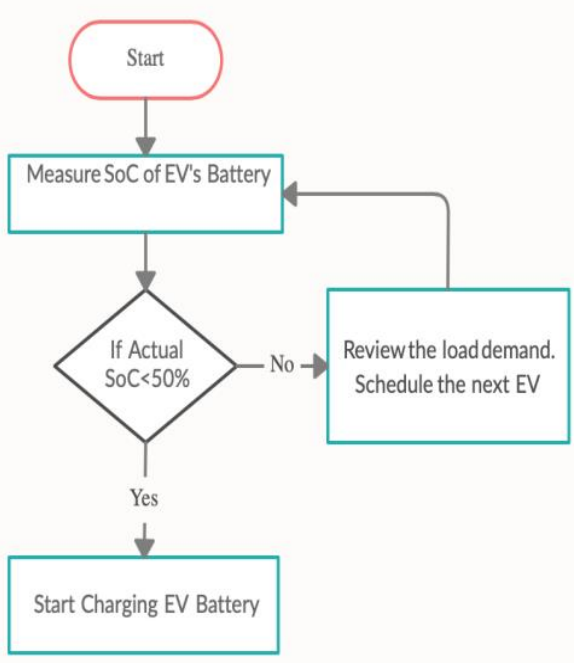

Grid Connection to EV charging station

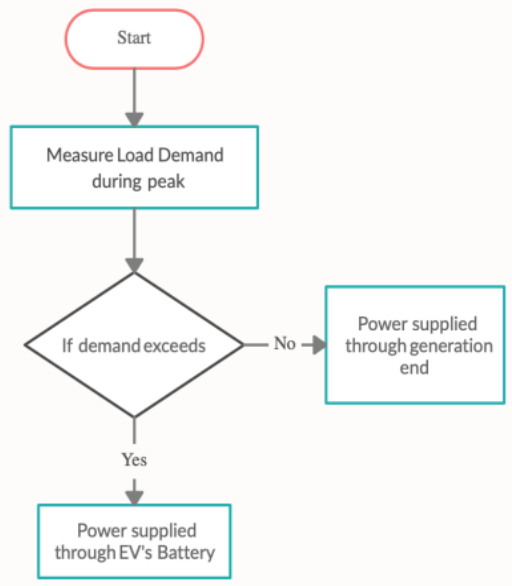

Grid connection from EV to Load end

VIII. RESULTS AND DISCUSSION

*All the observations mentioned in the following tables are taken by current and voltage sensors present in the Hardware Design of the experimentation.

Table I. Reading of power being consumed by load taken when power is sufficient for the load ( Case A)

\begin{tabular}{|l|l|l|l|}
\hline $\begin{array}{l}\text { Observation } \\
\text { No. }\end{array}$ & $\begin{array}{l}\text { Voltag } \\
(\text { Va) }\end{array}$ & $\begin{array}{l}\text { Current } \\
(\text { Ia) }\end{array}$ & $\begin{array}{l}\text { Power } \\
(\mathbf{P a})\end{array}$ \\
\hline 1. & $12 \mathrm{~V}$ & $0.11 \mathrm{~A}$ & $1.32 \mathrm{~W}$ \\
\hline 2. & $12 \mathrm{~V}$ & $0.16 \mathrm{~A}$ & $1.92 \mathrm{~W}$ \\
\hline
\end{tabular}

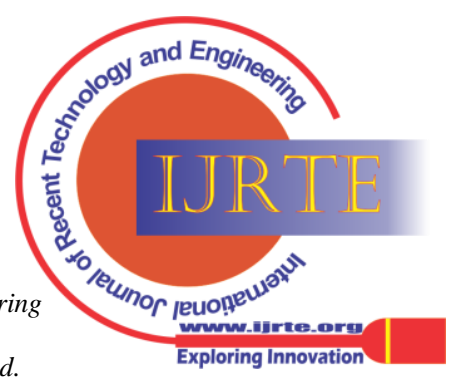


Table II. Readings being taken of power consumed by load when power is insufficient on the grid ( Case B)

\begin{tabular}{|l|l|l|l|}
\hline $\begin{array}{l}\text { Observation } \\
\text { No. }\end{array}$ & $\begin{array}{l}\text { Voltage } \\
\text { (Vb) }\end{array}$ & $\begin{array}{l}\text { Current } \\
\text { (Ib) }\end{array}$ & $\begin{array}{l}\text { Power } \\
(\mathbf{P b})\end{array}$ \\
\hline 1. & $12 \mathrm{~V}$ & $0.37 \mathrm{~A}$ & $4.44 \mathrm{~W}$ \\
\hline 2. & $12 \mathrm{~V}$ & $0.36 \mathrm{~A}$ & $4.32 \mathrm{~W}$ \\
\hline
\end{tabular}

Table III. Readings taken of power consumed by the load when excess/additional power required by the load is being supplied from the electric vehicles, ( Case C)

\begin{tabular}{|l|l|l|l|}
\hline $\begin{array}{l}\text { Observation } \\
\text { No. }\end{array}$ & $\begin{array}{l}\text { Voltag } \\
\text { e (Vc) }\end{array}$ & $\begin{array}{l}\text { Current } \\
\text { (Ic) }\end{array}$ & $\begin{array}{l}\text { Power } \\
(\text { Pc) }\end{array}$ \\
\hline 1. & $7 \mathrm{~V}$ & $0.45 \mathrm{~A}$ & $3.15 \mathrm{~W}$ \\
\hline 2. & $2.1 \mathrm{~V}$ & $0.08 \mathrm{~A}$ & $0.168 \mathrm{~W}$ \\
\hline
\end{tabular}

Formula Used- $\quad \mathrm{Pb}-\mathrm{Pa}=\mathrm{Pc}$

Where, $\mathrm{Pa}$ is the initial power consumed by the load.

$\mathrm{Pb}$ is the power consumed by load when power is insufficient on the grid.

Pc is the excess power that is being supplied through the EV

- In observation 1 of Cases A,B,C - SoC of EV's battery is more than $50 \%$

$\mathrm{Pa}=1.32 \mathrm{~W}$

$\mathrm{Pb}=4.44 \mathrm{~W}$

Excess Power $(\mathrm{Pb}-\mathrm{Pa})=4.44-1.32=3.12 \mathrm{~W}$

$\mathrm{Pc}=3.15 \mathrm{~W}$

For load demand to be fulfilled, the power supplied through EV's battery should be sufficient

$\because \mathrm{Pc}>\mathrm{Pb}-\mathrm{Pa}$

$\therefore$ Excess Load demand is being fulfilled by EV's battery

*In this prototype the excess load of 3.12 watts is being supplied by two Electric Vehicles represented by 2 Li-ion batteries of $3.7 \mathrm{~V}$ each.

- In observation 2 of Cases A,B,C - SoC of EV's battery is less than $50 \%$

$\mathrm{Pa}=1.92 \mathrm{~W}$

$\mathrm{Pb}=4.32 \mathrm{~W}$

Excess Power $(\mathrm{Pb}-\mathrm{Pa})=4.32-1.92=2.4 \mathrm{~W}$

$\mathrm{PC}=0.168 \mathrm{~W}$

For load demand to be fulfilled, the power supplied through EV's battery should be sufficient

$\because \mathrm{Pc}<\mathrm{Pb}-\mathrm{Pa}$

$\therefore$ Excess Load demand is not being fulfilled by EV's battery and battery starts charging.

\section{CONCLUSION}

The aforementioned results and conclusion argue on how during peak or additional load demand, energy can be supplied through Electric vehicles that are parked ideally at different Electric Vehicle Charging Stations provided these electric vehicles have sufficient State-of-Charge. On the other hand, if an electric vehicle is not sufficiently charged for it to be able to supply power to the grid, it is scheduled for charging during the off-peak times of load. This experimentation successfully shows how vehicle-to-grid technology can be implemented on a smaller scale which can further be expanded at a greater level. It pragmatically illustrates how a central grid controlling unit can govern the grid by managing energy during the time of peak load. In addition to the above, it depicts electric vehicles as a temporary energy storage resource which can be utilised when there is an excess demand over the limited generation capacity. Conclusively, in conjunction with the realistic world, this technology might turn out to be beneficial in current times when renewable sources are majorly taking over the energy production scenario.

\section{FUTURE SCOPE}

The advantages of V2G technology for various commercial and residential places are noticeable only when the electricity from parked car batteries is used where it is required. This technology helps in balancing the electricity demand and prevents any extra costs for establishing an electricity generation system at the same time no extra energy has to be consumed from the grid.

Buildings' ability to balance their electricity demand with V2G charging stations also helps the power grid on a larger scale. This technology can prove to be even more useful when renewable energy on the grid increases. In the current scenario where V2G is not part of the grid, reserve power plants are the main source of energy. This results in a hike in electricity prices during peak demand, since generating energy from these reserve power plants is a costly operation.

This technology is expected to become economically beneficial for most of the energy companies, thus increasing chances of introducing incentives to motivate consumers to actively take part, plug-in and enable their vehicle batteries to be used for V2G because, the technology, equipments, instruments, and vehicles compatible with the V2G technology are not sufficient. It can be expected that in the future, consumers are being rewarded if they are willing to enable their car batteries to be used as balancing elements.

\section{REFERENCES}

1. Arango Castellanos, J.D., Dhanasekaran Velayutha Rajan, H., Rohde, AK. et al. "Design and simulation of a control algorithm for peak-load shaving using vehicle to grid technology". SN Appl. Sci. 1, $951 \quad$ (2019). Available: https://link.springer.com/article/10.1007/s42452-019-0999-x

2. Khoucha F., Benbouzid M., Amirat Y., \& Kheloui A. - "Integrated energy management of a plug-in electric vehicle in residential distribution systems with renewables", IEEE Int. Symposium on Industrial Electronics-Brazil, 2015.2 Available: https://ieeexplore.ieee.org/document/7281557

3. J. Zhenhua and R. A. Dougal, "Control strategies for active power sharing in a fuel cell-powered battery-charging station" Industry Applications, IEEE Transactions on industry applications, vol. 40, pp. 917-924, $2004 . \quad$ Available: https://ieeexplore.ieee.org/document/1300749

4. K. Nansai, S. Tohno, M. Kono, M. Kasahara, and Y. Moriguchi, "Life-cycle analysis of charging infrastructure for electric vehicles" Applied Energy, vol. 70, pp. 251-265, 2001.

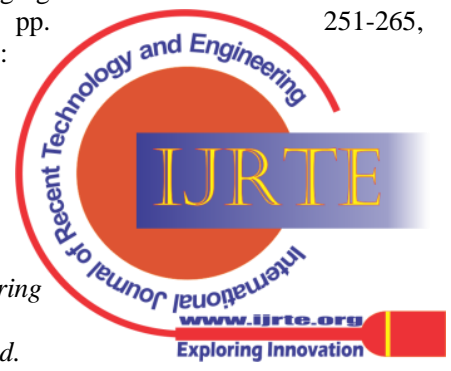


https://doi.org/10.1016/S0306-2619(01)00032-0

5. A. Vojdani, "Smart Integration" Power and Energy Magazine, IEEE, vol. $6, \quad$ pp. 71-79, $2008 . \quad$ Available: https://ieeexplore.ieee.org/document/4626381

6. B. K. Sovacool and R. F. Hirsh, "Beyond batteries: "An examination of the benefits and barriers to plug-in hybrid electric vehicles (PHEVs) and a vehicle-to-grid (V2G) transition" Energy Policy, vol. 37, pp. 1095- 1103, 2009. Available: https://doi.org/10.1016/j.enpol.2008.10.005

7. Pritesh Bhila Ahire, Pratik Kusan Bedase, Shubham Bhujang Tangade and Pankaj Ramesh Shelke - "Review on: Conservation and Generation by Vehicle-to-Grid in Smart Parking", 7th Int Conference on Science, Technology and Management, Nashik, 2017. Available: http://data.conferenceworld.in/ICSTM7/52.pdf

8. Tu Yiyun, Li Can, Cheng Lin and Le Lin - "Research on Vehicle-togrid Technology", IEEE- Int. Conference on Computer Distributed Control and Intelligent Environmental Monitoring 2011. Available: https://doi.org/10.1109/CDCIEM.2011.194

9. Pramod Kumar K and Hari Om Bansal - "Commercial Sustainability of Vehicle-to-Grid Concept: An Overview", International Conference on Emerging Trends in Communication, Control and Computing, 2020 Available: https://doi.org/10.1109/ICONC345789.2020.9117523

10. Pritish Pani, Abhishek R Athreya, Aishwarya Panday, Hari Om Bansal and H. P. Agrawal- "Integration of the vehicle to grid technology" Int. Conference on Electrical and Electronics Engineering, Malaysia, $2015 . \quad$ Available: http://dx.doi.org/10.1109/EnergyEconomics.2015.7235108

11. MD. Anamul Haque, "Vehicle to grid technology", 2017 Available: https://www.slideshare.net/anamulhaque790693/vehicle-to-gridtechnology

12. Toyota Tsusho Corporation and Chubu Electric Power Co., Inc., "The Overview of the V2G Demonstration Project", Available: https://www.toyotatsusho.com/english/press/upload_files/1906051400R_en.pdf

13. Virta, "Vehicle to Grid", Available: https://www.virta.global/vehicle-to-grid-v2g

14. Nuvve Corp., "V2G Concept", Available https://nuvve.com/technology/

15. Thomas Raffeiner, "How does V2G work?", The Mobility House, Available: https://www.mobilityhouse.com/usa_en/vehicle-to-grid

\section{AUTHORS PROFILE}

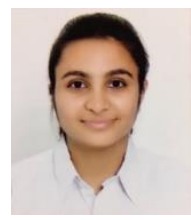

Ms. Bakul Vani, B.Tech student at Department of Electrical Engineering, Medi-Caps University, Indore, Madhya Pradesh, India. She has also been a part of a project based on "Development of user interface for EV Charging Stations". She wishes to work in the field of Energy Management in the near future. bakulvani@gmail.com

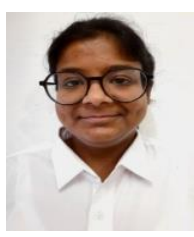

Ms. Devyani Chaturvedi, B.Tech student at Department of Electrical Engineering, Medi-Caps University, Indore, Madhya Pradesh, India. She has also been a part of a project based on "Development of user interface for EV Charging Stations". She plans to study for a Masters in Business Administration in coming years.devyani2808@gmail.com

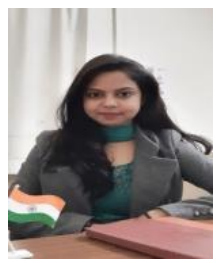

Ms. Preeti Yadav, Assistant Professor at the department of Electrical Engineering Medi-Caps University, Indore, India. She is a Post Graduate in Digital Instrumentation and techniques from Shri Govindram Seksaria Institute of Technology and Science, Indore, Madhya Pradesh, India. She has 5 years of work experience in technical teaching. She has developed a successful working project model on Solar powered Electric Vehicle. She has also done research on "Forecasting of Solar Radiation of an Area by Using Artificial Neural Network Technique through Matlab" and also published a research paper for the same. She has Guided many projects on Electric Vehicles like "Modeling and Integration of Electric Vehicle Charging Stations", "Metering and billing system for the EV Charging Station", "Battery Management System for EV", " Development of user interface for Charging stations of EV", "Development of user interface for locating proper charging stations for EV users". She has also designed the curriculum for three Courses "Electric Vehicle", "EV- Charging Infrastructure" and "Industrial instrumentation and sensors" for Medi-
Caps University. Currently, Ms. Yadav is working as a team leader for the development of Electric Vehicle laboratory setup for the University. She is also involved in developing a City model plan for Electric Vehicle Charging Infrastructure.preetiyadav1225@gmail.com 